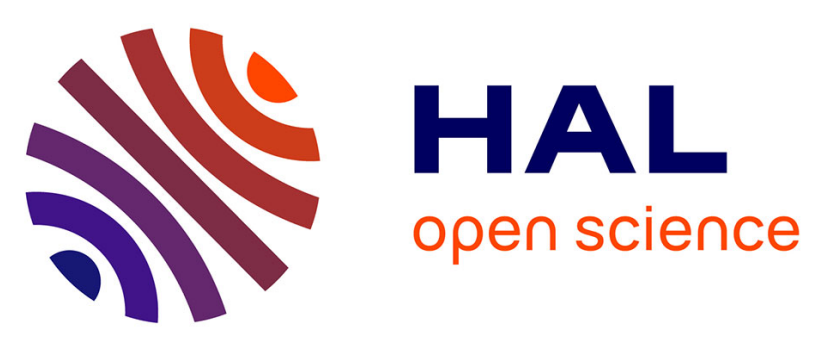

\title{
Biopolymers-calcium phosphate antibacterial coating reduces the pathogenicity of internalized bacteria by mesenchymal stromal cells
}

Marie Dubus, Jennifer Varin-Simon, Pierre Prada, Loïc Scomazzon, Fany Reffuveille, Halima Alem, Fouzia Boulmedais, Cédric Mauprivez, Hassan Rammal, Halima Kerdjoudj

\section{To cite this version:}

Marie Dubus, Jennifer Varin-Simon, Pierre Prada, Loïc Scomazzon, Fany Reffuveille, et al.. Biopolymers-calcium phosphate antibacterial coating reduces the pathogenicity of internalized bacteria by mesenchymal stromal cells. Biomaterials Science, 2020, 20, 10.1039/D0BM00962H . hal-02965407

\section{HAL Id: hal-02965407 https://hal.science/hal-02965407}

Submitted on 13 Oct 2020

HAL is a multi-disciplinary open access archive for the deposit and dissemination of scientific research documents, whether they are published or not. The documents may come from teaching and research institutions in France or abroad, or from public or private research centers.
L'archive ouverte pluridisciplinaire HAL, est destinée au dépôt et à la diffusion de documents scientifiques de niveau recherche, publiés ou non, émanant des établissements d'enseignement et de recherche français ou étrangers, des laboratoires publics ou privés. 


\section{Biopolymers-Calcium Phosphate Antibacterial Coating Reduces the Pathogenicity of Internalized Bacteria by Mesenchymal Stromal Cells}

Marie Dubus ${ }^{1,2}$, Jennifer Varin-Simon ${ }^{1}$, Pierre Prada ${ }^{1}$, Loïc Scomazzon ${ }^{1}$, Fany Reffuveille ${ }^{1,3}$, Halima Alem ${ }^{4}$, Fouzia Boulmedais ${ }^{5}$, Cédric Mauprivez ${ }^{1,2,6}$, Hassan Rammal ${ }^{1,2}$, Halima Kerdjoudj $^{1,2, *}$

1. Université de Reims Champagne Ardenne, EA 4691, Biomatériaux et Inflammation en Site Osseux (BIOS), Reims, France.

2. Université de Reims Champagne Ardenne, UFR d'Odontologie, Reims, France.

3. Université de Reims Champagne Ardenne, UFR de Pharmacie, Reims, France.

4. Université de Lorraine, CNRS, Institut Jean Lamour (UMR 7198), Nancy, France.

5. Université de Strasbourg, CNRS, Institut Charles Sadron, UPR 22, Strasbourg, France.

6. Pôle Médecine bucco-dentaire, Hôpital Maison Blanche, Centre Hospitalier Universitaire de Reims, France.

*_Correspondance: halima.kerdjoudj@univ-reims.fr ; Tel: (+33) 326918012 


\begin{abstract}
A multifunctional material system that kills bacteria and drives bone healing is urgently sought to improve bone prosthesis. Herein, the osteoinductive coating made of calcium phosphate/chitosan/hyaluronic acid, named Hybrid, was proposed as an antibacterial substrate for stromal cell adhesion. This Hybrid coating possesses a contact-killing effect reducing by 90\% the viability of Gram-positive Staphylococcus aureus (S. aureus) and Gram-negative Pseudomonas aeruginosa ( $P$. aeruginosa) strains after $48 \mathrm{~h}$ of contact. In addition to the production of immunomodulatory mediators, Wharton's jelly (WJ-SCs), dental pulp (DPSCs) and bone marrow (BM-MSCs) derived stromal cells were able to release antibacterial and antibiofilm agents effective against $S$. aureus and $P$. aeruginosa strains, respectively. Studying the effect of the Hybrid coating on the internalization of $S$. aureus by the stromal cells, in acutemimicking bone infection, highlighted an increase in the bacteria internalization by DPSCs and BM-MSCs when cultured on the Hybrid coating versus uncoated glass. Despite the internalization, Hybrid coating showed a beneficial effect by reducing the pathogenicity of the internalized bacteria. The formation of biofilm was reduced by at least $50 \%$ in comparison to internalized bacteria by stromal cells on uncoated glass. This work opens the route for the development of innovative antibacterial coatings by taking into account the internalization of bacteria by stromal cells.
\end{abstract}

Keywords: antibacterial coating, mesenchymal stromal cells, bacteria, S. aureus internalization 


\section{Introduction}

When prosthesis is implanted in the body, a competition between the host's cells and the bacteria occurs at the implant/bone interface, compromising its osseointegration. Despite strict aseptic procedures, bacterial infections occur and contribute to heavy health and socioeconomic burdens worldwide. Standard treatments for infected bone include the removal of necrotic bone fragments, local and/or systemic administration of antibiotics, and reconstruction of bone defects by bone grafts. These treatments are time consuming, do not always yield satisfactory outcomes, and contribute to bacteria antibiotic resistance emergence. ${ }^{1,2}$ The development of biomaterials with intrinsic antibacterial properties was proposed to impede the bacterial growth, to reduce the time of treatment and the total costs. Biomaterial coatings have provided new weapons against bacteria attachment and/or growth. Myriad of surface coatings, based on the anchorage of antibacterial compounds, have been developed, resulting in bacteria membrane disruption and bacteria lysis. ${ }^{3-8}$ To our knowledge, up to date, four technologies are available in clinics: (i) silver, (ii) iodine, (iii) gentamicin/poly(D,L-lactide) and (iv) fast resorbable hyaluronic acid/poly(D,L-lactide) hydrogel coatings. ${ }^{4}$ Besides antibiotic resistance of bacteria, the genotoxicity and/or cytotoxicity of released ions and the quick resorption of the hydrogel make long-term side effects quite unlikely.

Combining biomaterials with mesenchymal stromal cells (MSCs) has generated significant medical consideration for bone reconstructive and/or regenerative applications. In clinical trials and in terms of regenerative medicine, bone marrow (BM)-MSCs are the gold standard. However, several disadvantages in their use exist including the availability, effectiveness, and invasive and painful procedures required for their isolation. ${ }^{9,10}$ MSCs can also be isolated from various tissue types including Wharton's jelly umbilical cord and dental pulp tissues. Wharton's jelly derived stromal cells (WJ-SCs) and dental pulp derived stromal cells (DPSCs) are noteworthy for their ease of accessibility from umbilical cord and healthy teeth (i.e. extraction 
of non-fully erupted third molars). Regarded as disposable tissues, harvesting cells from umbilical cord or teeth do not raise ethical concerns. WJ-SCs and DPSCs have the capacity for self-renewal and potential for multilineage differentiation, ${ }^{11-13}$ constituting ideal candidates to replace BM-MSCs. One of the most intriguing properties of BM-MSCs is their antimicrobial properties responsible of the bacterial clearance in clinical and preclinical models of sepsis, ${ }^{14}$ acute respiratory distress syndrome, ${ }^{15}$ cystic fibrosis over-infection, ${ }^{16,17}$ and secondary infection in patients positively diagnosed with COVID-19. ${ }^{18}$ The strong antibacterial effect of BM-MSCs is linked to the release of antimicrobial agents such as cathelicidin LL-37, human $\beta$-defensin-2, hepcidin, and lipocalin-2 and also through their immunomodulatory action on the host's immune response. ${ }^{16,19-21}$ To our knowledge, no study has been reported so far on the antibacterial properties of either WJ-SCs and DPSCs conditioned media.

Calcium phosphate ceramics have been widely used for bone regenerative medicine due to their ability to induce bone formation. ${ }^{22-25}$ We recently elaborated a bioactive and osteoinductive calcium phosphate/chitosan/hyaluronic acid (Hybrid) coating able to boost the early differentiation of stromal cells into osteoblast-like lineage. Aside from maintaining the stromal cells paracrine production of osteoprotegerin, Hybrid coating also induces the production of angiogenic growth factors required for bone vascularization, such as the vascular endothelial growth factor. ${ }^{26-28}$ Hybrid coating was shown to limit the adhesion of implant-associated Staphylococcus aureus (S. aureus) without studying the underlying antibacterial mechanism. ${ }^{26}$ Prosthesis-related infections are mainly due to contamination by the commensal microbiota of the skin such as $S$. aureus. ${ }^{29-31}$ Because of biofilm mode of growth, these bacteria can attach and persist on bone or on implanted prosthesis. Studies dealing with the interaction of S. aureus with osteoblasts or stromal cells showed a bacterial adhesion to the cell membranes, followed by their internalization. ${ }^{29,32-35} \mathrm{~S}$. aureus produce microbial surface component recognising adhesive matrix molecules, involved in the bacterial interaction with extracellular matrix 
proteins, such as fibronectin ${ }^{36}$. Fibronectin is thought to be used by the bacteria to form a molecular bridge between the bacterial surface proteins and $\alpha 5 \beta 1$ integrin. This latter is detected as early marker on osteoblasts during osteoprogenitor differentiation. ${ }^{37,38}$ This could favor the S. aureus internalization during the differentiation of stromal cells.

A multifunctional material system that kills bacteria and drives bone regeneration is urgently sought to improve bone prosthesis. To the best of our knowledge, the influence of an antibacterial coating on $S$. aureus internalization by stromal cells and their function was never addressed. Indeed, all the literature dealing with S. aureus internalization is focused on the internalization mechanism of different types of cells including osteoblasts and stromal cells cultured on TCPS. ${ }^{29,32-35}$ To this end, this work investigates whether Hybrid coating could be used to potentially fight bacterial infection in bone, by killing bacteria and minimising stromal cells/bacteria interaction. We first investigated the antibacterial effect of the Hybrid coating against two bacteria strains, Gram-positive S. aureus, responsible for $75 \%$ of bone infections, ${ }^{31}$ and Gram-negative Pseudomonas aeruginosa ( $P$. aeruginosa), the most studied bacterium for biofilm formation. ${ }^{39}$ Antibacterial and immunomodulatory effects of WJ-SCs and DPSCs (versus BM-MSCs) were also tested against both strains. Finally, stromal cells cultured on Hybrid coating were challenged with $S$. aureus to analyze the underlying internalization and the pathogenicity of the internalized bacteria. 


\section{Material and methods}

Materials. Calcium nitrate $\left(\mathrm{Ca}\left(\mathrm{NO}_{3}\right)_{2}, 4 \mathrm{H}_{2} \mathrm{O}\right)$, diammonium hydrogen phosphate $\left(\left(\mathrm{NH}_{4}\right)_{2} \mathrm{HPO}_{4}\right)$, sodium dihydrogen phosphate hydrate $\left(\mathrm{NaH}_{2} \mathrm{PO}_{4}\right)$, Tris(hydroxymethyl) aminomethane (Tris), calcium chloride hydrate $\left(\mathrm{CaCl}_{2}, 2 \mathrm{H}_{2} \mathrm{O}\right)$, sodium chloride and chitosan (75-85\% deacetylated, low molecular weight) from Sigma and hyaluronic acid (200 kDa) from Lifecore Biomedical were used without further purification. Salt solutions were prepared in ultrapure water (Millipore ${ }^{\circledR}$ ). For Hybrid coating build-up, $\mathrm{CaCl}_{2}, 2 \mathrm{H}_{2} \mathrm{O}(0.32 \mathrm{M})$ and chitosan $0.3 \mathrm{mg} / \mathrm{mL}$ were dissolved in $\mathrm{NaCl}(0.15 \mathrm{M}) / \mathrm{HCl}(2 \mathrm{mM})$ buffer, $\mathrm{pH} 4$ whereas $\mathrm{NaH}_{2} \mathrm{PO}_{4}(0.19$ M) and hyaluronic acid $0.3 \mathrm{mg} / \mathrm{mL}$ were prepared in $\mathrm{NaCl}(0.15 \mathrm{M})$ buffer $\mathrm{pH} 10$. The sprayed chitosan/hyaluronic molar ratio in monomer is of 2 , close to the optimum of build-up. ${ }^{40}$ For Inorganic coating build-up, a calcium solution of $\mathrm{Ca}\left(\mathrm{NO}_{3}\right)_{2} \cdot 4 \mathrm{H}_{2} \mathrm{O}(0.32 \mathrm{M})$ and a phosphate solution of $\left(\mathrm{NH}_{4}\right)_{2} \mathrm{HPO}_{4}(0.2 \mathrm{M})$ were prepared in Tris buffer $(10 \mathrm{mM}$ Tris, $\mathrm{pH} 4$ and $\mathrm{pH} 10$ respectively). The build-up of Hybrid- and Inorganic coatings was performed on glass coverslip or collagen membrane (Bio-Gide ${ }^{\circledR}$ ) as described previously. ${ }^{26,28}$

Physico-chemical characterizations. Fourier Transform Infrared spectrometry (FTIR) experiments were performed on a Vertex 70 spectrometer (Bruker, Germany) using a DTGS detector. Spectra were recorded in the Attenuated Total Reflection (ATR) mode using single reflexion diamond ATR by averaging 128 interferograms between 600 and $4000 \mathrm{~cm}^{-1}$ at $2 \mathrm{~cm}^{-1}$ resolution, using Blackman-Harris three-term apodization and Bruker OPUS/IR software (version 7.5). Transmission Electron Microscopy (TEM) investigations were performed with a JEOL ARM 200F cold FEG TEM/STEM (point resolution $0.19 \mathrm{~nm}$ in TEM mode and $0.078 \mathrm{~nm}$ in STEM mode) fitted with a GIF Quantum ER. HR-TEM pictures were performed with a JEOL ARM 200F cold FEG (point resolution $0.19 \mathrm{~nm}$ ) fitted with a GIF Quantum ER. Finally, scanning electron microscopy-energy dispersive X-ray spectroscopy 
investigations were performed with SEM-EDX, JEOL JSM 6010LA. The X-ray spectra were acquired at primary beam energy of $10 \mathrm{keV}$ with an acquisition time of $30 \mathrm{~s}$.

Coatings' antibacterial properties. The strains used in the study consisted of Staphylococcus aureus (S. aureus) and Pseudomonas aeruginosa (P. aeruginosa) wild-type strains from Institut Pasteur Collection (CIP 53.154 and CIP 82.118, respectively). After a preculture of $18 \mathrm{~h}$ in nutritive broth, $500 \mu \mathrm{L}$ of minimal medium (MM: $62 \mathrm{mM}$ potassium phosphate buffer, $\mathrm{pH}$ 7.0, $7 \mathrm{mM}\left[\left(\mathrm{NH}_{4}\right)_{2} \mathrm{SO}_{4}, 2 \mathrm{mM} \mathrm{MgSO} 4,10 \mu \mathrm{M} \mathrm{FeSO}_{4}\right]$ with $0.4 \%(w / v)$ glucose $)$, containing about $10^{6} \mathrm{CFU} / \mathrm{mL}$ (controlled by enumeration), were deposited on UV-decontaminated (20 min) Hybrid and Inorganic coatings, for $4 \mathrm{~h}, 24 \mathrm{~h}$ or $48 \mathrm{~h}$ at $37^{\circ} \mathrm{C}$. Both coatings were rinsed with MM, immersed in $2 \mathrm{~mL}$ of $\mathrm{MM}$ and then sonicated for $5 \mathrm{~min}$. Serial dilutions were further plated on TCS agars plates (Biokar) and colony counts were performed to evaluate adhesive activity.

Scanning electron microscopy with a field emission gun (FEG-SEM). Hybrid and Inorganic coatings after $48 \mathrm{~h}$ of bacterial incubation were rinsed with $\mathrm{MM}$, before their fixation with $2.5 \%$ $(w / v)$ glutaraldehyde (Sigma-Aldrich) at room temperature for $1 \mathrm{~h}$. Samples were then rinsed twice with Phosphate-Buffered Saline (PBS), dehydrated in graded ethanol solutions from 50 to $100 \%$ and desiccated in hexamethyldisilazane (Sigma-Aldrich) for $10 \mathrm{~min}$. After air-drying at room temperature, samples were sputtered with a thin gold-palladium film using a JEOL ion sputter JFC 1100 instrument. FEG-SEM investigations were performed with a FEG-SEM (JEOL JSM-7900F, France), and images were acquired from secondary electrons at primary beam energy at $5 \mathrm{kV}$. Uncoated collagen membrane was used as a control.

Cell culture. The studies involving human participants were reviewed and approved by our local Research Institution and were conducted with informed patients in accordance with the usual ethical legal regulations (Article R 1243-57). All procedures were done in accordance with our authorization and registration number DC-2014-2262 given by the National "Cellule 
de Bioéthique" of "Agence de Biomédecine". The patients/participants provided their written informed consent to participate in this study. Human bone marrow (BM) samples were collected by aspiration from femoral necks of patients (aged between 40 and 70 years old) undergoing total hip replacement. Aspirated bone marrow was diluted in Phosphate-Buffered Saline (PBS, $v / v)$ and centrifuged at $300 g$ for $10 \mathrm{~min}$ and primary cultures (P0) were then initiated by plating isolated mononuclear cells at $5 \times 10^{5} \mathrm{cells} / \mathrm{cm}^{2}$. Healthy pulp tissues were isolated from the caries-free teeth of patients undergoing extraction of non-fully erupted third molars. Healthy fresh human umbilical cords were harvested after full-term births. Wharton's jelly derived stromal cells (WJ-SCs) and dental pulp stromal cells (DPSCs) were enzymatically isolated using type B collagenase $(1 \mathrm{mg} / \mathrm{mL})$ and trypsin $(5 \mathrm{x})$ mixture. WJ-SCs, DPSCs and BM-mesenchymal stromal cells (BM-MSCs) were all cultured in $\alpha$-MEM (Lonza) supplemented with $10 \%$ decomplemented fetal bovine serum (FBS), $1 \%$ Penicillin/Streptomycin/Amphotericin B (PSA) and $1 \%$ Glutamax $^{\circledR}(v / v$, Gibco) and maintained in a humidified atmosphere of $5 \% \mathrm{CO}_{2}$ at $37^{\circ} \mathrm{C}$ with a medium change every two days. Reaching sub-confluence, BM-MSCs were amplified at density of $1 \times 10^{3} \mathrm{cell} / \mathrm{cm}^{2}$ until the second passage, whereas both DPSCs and WJ-SCs were amplified at density of $3 \times 10^{3}$ cell $/ \mathrm{cm}^{2}$ until the third passage. WJ-SCs, DPSCs and BM-MSCs were characterized by flow cytometry (BD LSRFortessa flow, BD Biosciences, San Jose, CA, USA) through the expression of CD73, CD90, CD44, CD105, CD34, CD45, and HLA-DR and then used in our experimental procedure at the fourth passage.

Cells' antibacterial properties. Reaching sub-confluence, cells in T75 flask were washed twice with PBS then cultured $72 \mathrm{~h}$ in $5 \mathrm{~mL}$ of PSA-free $\alpha$-MEM medium (basal medium). Cells' conditioned media $(\mathrm{CM})$ were then collected and conserved at $-80^{\circ} \mathrm{C}$ before use. Diluted overnight cultures of $S$. aureus and P. aeruginosa (1/100) were cultured in $100 \mu \mathrm{L}$ of WJ-SCsCM, DPSCs-CM and BM-MSCs-CM for $24 \mathrm{~h}$ at $37^{\circ} \mathrm{C}$. The planktonic growth was evaluated 
through absorbance measurement at $600 \mathrm{~nm}$, while the formation of biofilm was evaluated by crystal violet staining. Briefly, 96-well plates were gently washed with water and $100 \mu \mathrm{L}$ of $0.2 \%$ crystal violet were deposited per well. After 20 min of incubation, plates were washed with PBS and $100 \mu \mathrm{L}$ of $95 \%$ ethanol were added to each well before absorbance measurement at $595 \mathrm{~nm}$. Basal medium was used as control.

Cytometric Bead Array (CBA). WJ-SCs, DPSCs and BM-MSCs were seeded on both coatings at $24 \times 10^{3}$ cells $/ \mathrm{cm}^{2}$ in $\alpha$-MEM complete medium. After a week of culture, WJ-SCsCM, DPSCs-CM and BM-MSCs-CM were kept at $-20^{\circ} \mathrm{C}$ before analysis. Secreted levels of interleukin (IL)-8, IL-6 and Monocyte Chemoattractant Protein-1 (MCP-1) were assessed using (BD ${ }^{\mathrm{TM}}$ CBA) Human IL-8 Flex Set, Human IL-6 Flex Set, and Human MCP-1 Flex Set (BD Biosciences), respectively, according to the manufacturer's instructions. Results were analysed using LSRFortessa flow cytometer. Results were normalized to CMs of stromal cells cultured on uncoated substrate.

Cells' infection. WJ-SCs, DPSCs and BM-MSCs were seeded on build-up coatings (and on uncoated substrate as control) at $24 \times 10^{3}$ cells $/ \mathrm{cm}^{2}$ in $\alpha-M E M$ complete medium. After a week of culture, cells were washed with PBS and cultured, overnight, with $\alpha$-MEM PSA-free medium. Cells were then challenged for $3 \mathrm{~h}$ with $S$. aureus to obtain a multiplicity of infection (MOI) 30:1. ${ }^{33}$ After $3 \mathrm{~h}$ of interaction, cells were washed with PBS and incubated for $1 \mathrm{~h}$ with basal medium supplemented by $100 \mu \mathrm{g} / \mathrm{mL}$ of gentamicin (Fisher scientific). Cells were then lysed with $0.1 \%$ Triton X-100 for 5 min and cell lysates were plated on TCS agars to evaluate the rate of viable intracellular $S$. aureus.

Biofilm formation by internalized bacteria. One colony of internalized bacteria (isolated on agar plate after $3 \mathrm{~h}$ of infection) was added in $500 \mu \mathrm{L}$ of nutritive broth (Bio-Rad) in 48 -well plate for $24 \mathrm{~h}$ at $37^{\circ} \mathrm{C}$. Plates were then gently washed and biofilm formation was evaluated as 
previously described. All results were normalized to formed biofilm by internalized bacteria by cells cultured on uncoated substrate (bacteria control).

Statistical analysis. All statistical analyses were performed using GraphPad Prism 6 software. All cell experiments were performed with four independent donors in duplicate. For each bacteria type, at least three independent enumerations were carried out for each surface adhesion experiment and all type of surface was tested in triplicate. Biofilm experiments were performed in triplicate. All results were represented as histograms (mean \pm SEM), statistical analysis were performed using Mann \& Whitney test. For each test, a value of $p<0.05$ was accepted as statistically significant $p$ (rejection level of the null-hypothesis of equal means). 


\section{Results and discussion}

Antibacterial properties of the Hybrid coating. The Hybrid coating possesses excellent bioactivity and capability of inducing an overwhelmingly positive response of stromal cells and monocytes in favor of bone regeneration..$^{26-28,41}$ Obtained by a versatile simultaneous spraying of interacting species, this coating of about $1 \mu \mathrm{m}$ in thickness is composed of amorphous calcium phosphate and carbonated poorly crystalline hydroxyapatite, with a $\mathrm{Ca} / \mathrm{P}$ ratio close to 1.30, wrapped within chitosan/hyaluronic acid polysaccharide complex (Fig. 1A and B). ${ }^{26}$ Herein, the antibacterial properties of the Hybrid coating was tested against $S$. aureus and $P$. aeruginosa. All the results were compared to the Inorganic coating made of amorphous calcium phosphate and poorly crystalline hydroxyapatite, with a $\mathrm{Ca} / \mathrm{P}$ ratio close to $1.20 .{ }^{42}$ The complete physico-chemical characterization of Hybrid and Inorganic coatings are provided (Fig. 1 and Table SI-1). ${ }^{26,42}$ Chitosan/hyaluronic coating showed an unsuccessful build-up on the glass coverslip and was discarded as a control. 


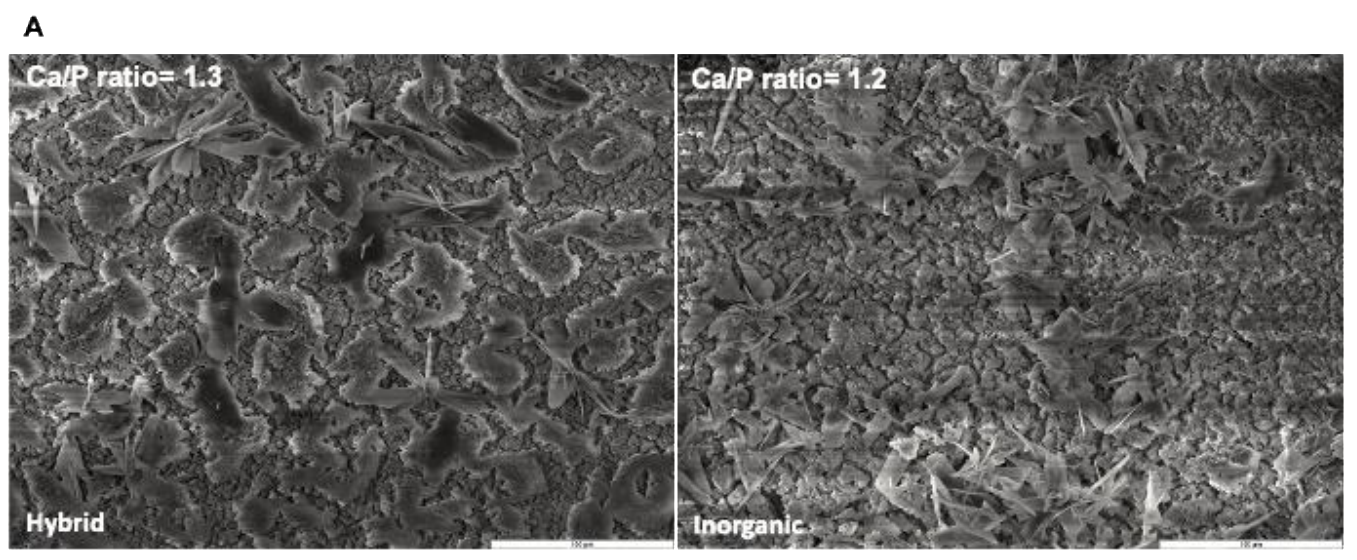

B
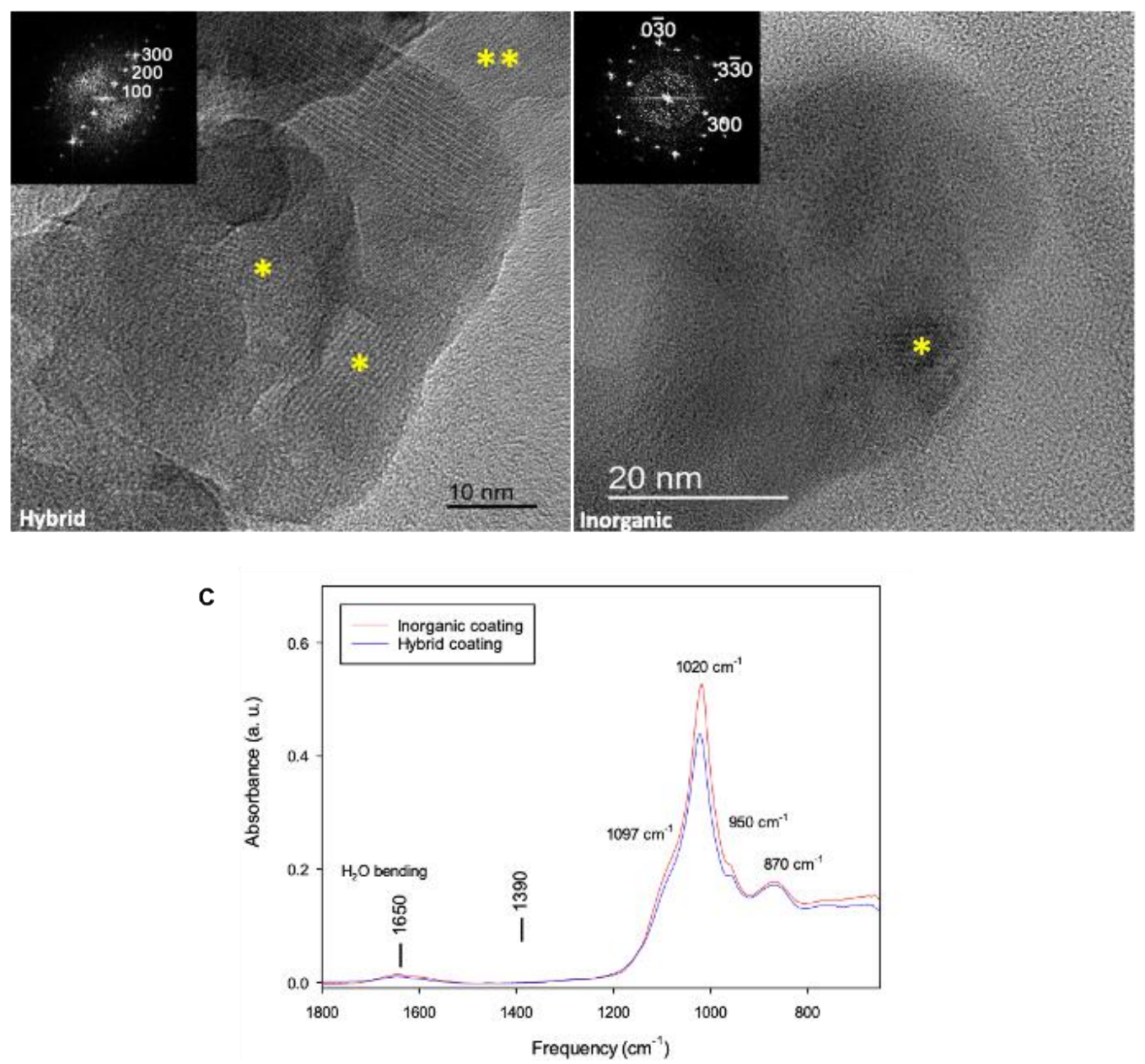

Figure 1: Morphological and physico-chemical characterizations of the Hybrid and Inorganic coatings. A: Top views of representative SEM images and $\mathrm{Ca} / \mathrm{P}$ ratios evaluated by EDX (scale bars indicate $100 \mu \mathrm{m}$ ). B: HR-TEM images of the crystal-like structure (inserts represent the extracted FFT pattern and the assigned plans, scale bars indicate 10 and $20 \mathrm{~nm}$, respectively). * and ** indicate mineral crystal and amorphous film, respectively. C: ATRFTIR spectra of Inorganic and Hybrid coatings. The peaks at 1097, 1020, 950 and $870 \mathrm{~cm}^{-1}$ are attributed to hydroxyapatite phase. 
The percentage of alive $S$. aureus and P. aeruginosa on both coatings was monitored after 4, 24 and $48 \mathrm{~h}$ of incubation. In all cases, adhered bacteria were detected after $4 \mathrm{~h}$ of contact. 24 h later, P. aeruginosa were more sensitive to the Hybrid coating in comparison to S. aureus, as a sharp decrease in $\%$ of alive bacteria was observed (Fig. 2A and 2B). After $48 \mathrm{~h}$ of contact, the $\%$ of alive $S$. aureus and $P$. aeruginosa were significantly reduced on the Hybrid coating in comparison to the Inorganic one (> $90 \%$ of reduction, $p<0.006)$. When the coatings were built on clinical grade collagen membranes, ${ }^{28}$ a significant reduction in $S$. aureus $(53 \%)$ and $P$. aeruginosa ( $87 \%$ ) alive bacteria was obtained after $48 \mathrm{~h}$ of contact on the Hybrid coating versus the Inorganic one (Fig. 2C and 2D). These results suggest that chitosan/hyaluronic acid polysaccharide complexes provide antibacterial properties to the Hybrid coating through a contact killing process. ${ }^{43,8}$ 

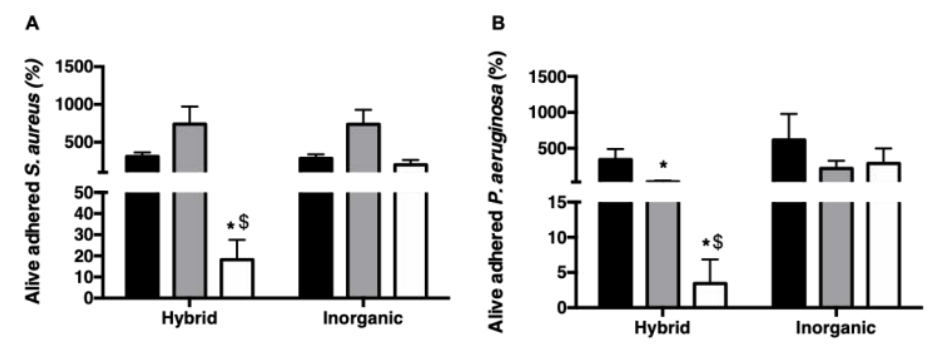

ש 4h
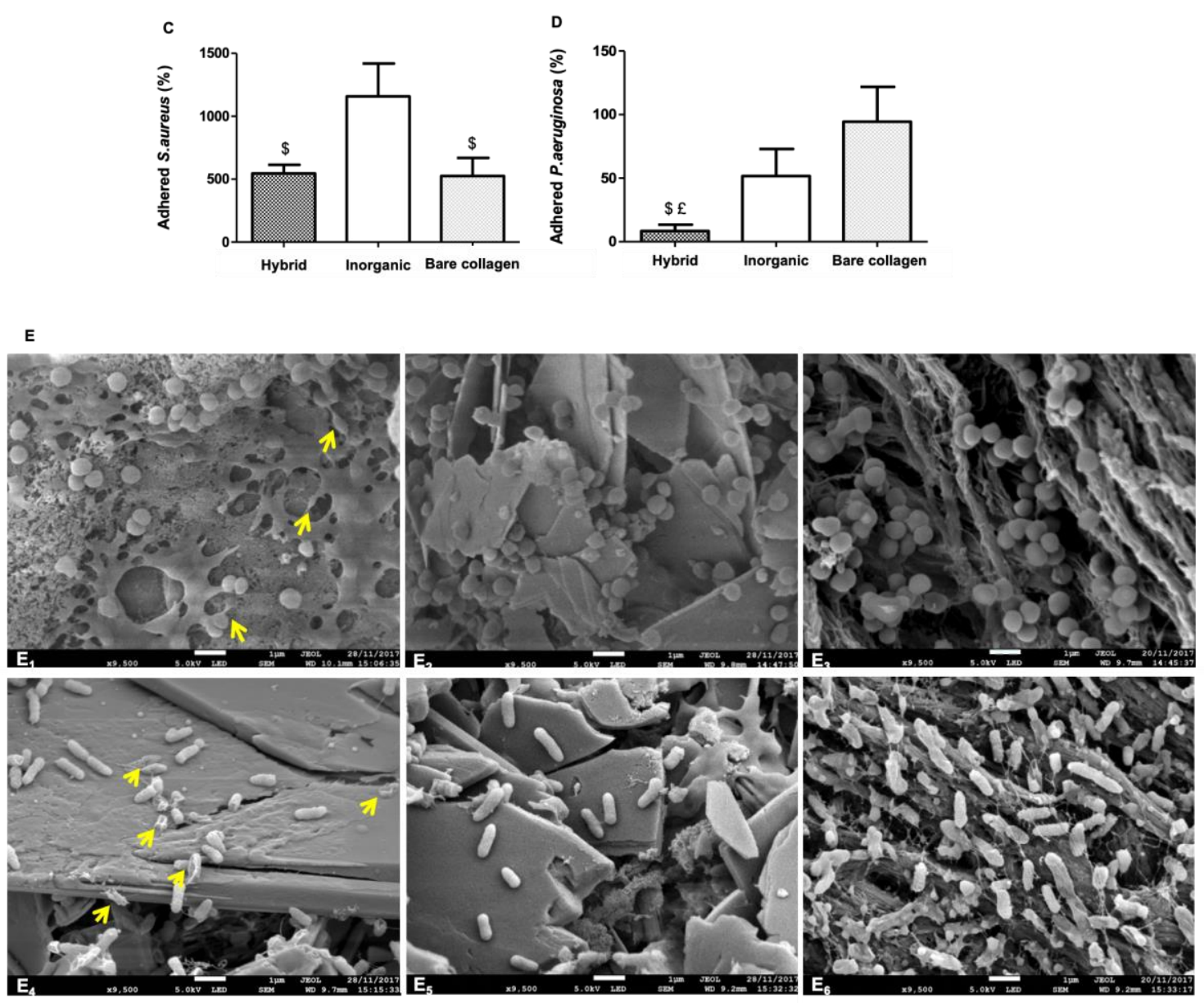

Figure 2: Antibacterial properties of the Hybrid and Inorganic coating. (A) Percentage of alive adhered S. aureus and (B) P. aeruginosa on the Hybrid- and Inorganic coatings over the time ( $\mathrm{n}=4$, * versus previous time; $\$$ versus inorganic, $p<0.05$; Mann \& Whitney test). (C) Percentage of alive adhered S. aureus and (D) P. aeruginosa on respectively the Hybrid-, Inorganic coated and bare collagen membranes after $48 \mathrm{~h}$ of incubation ( $\mathrm{n}=4$, \$ versus inorganic; £ versus bare collagen; Mann \& Whitney test). (E) Bacterial adhesion and morphological changes imaged by FEG-SEM, after $48 \mathrm{~h}$ of contact of $S$. aureus with the Hybrid- $\left(\mathrm{E}_{1}\right)$, Inorganic coated $\left(\mathrm{E}_{2}\right)$ and bare $\left(\mathrm{E}_{3}\right)$ collagen membranes and of $P$. aeruginosa with the Hybrid- $\left(\mathrm{E}_{4}\right)$, Inorganic coated $\left(\mathrm{E}_{5}\right)$ and bare $\left(\mathrm{E}_{6}\right)$ collagen membranes. Arrows showed S. aureus elongation and P. aeruginosa cytoplasm contraction on Hybrid coating (Scale bars $=1 \mu \mathrm{m})$. 
Evaluation of bacterial adhesion and morphological changes showed the rupture of the bacterial wall on the Hybrid-coated-collagen membrane. On the uncoated collagen membrane and the Inorganic-coated collagen membrane, bacteria organised themselves in grape-like clusters and kept their structural integrity. S. aureus and P. aeruginosa morphologies were altered in different way (Fig. 2E). The Hybrid coating induced in S. aureus strain an elongation and a disaggregation of grape-like clusters and in P. aeruginosa strain a cytoplasm contraction with an increase in wall roughness (Fig. 2E, yellow arrows). The contact-killing modes begin with interactions at the bacteria surface compromising their wall integrity. ${ }^{43}$ Hyaluronic acid has antiadhesive and antibiofilm activities ${ }^{44,45}$ while chitosan is known to interact with bacterial, causing bacteria wall alterations and death. ${ }^{46}$ Polyanionic teichoic acid, ensuring S. aureus membrane stability, provides a molecular linkage for the polycationic chitosan, disturbing the cell membrane functions (Scheme 1). ${ }^{47,48}$

A

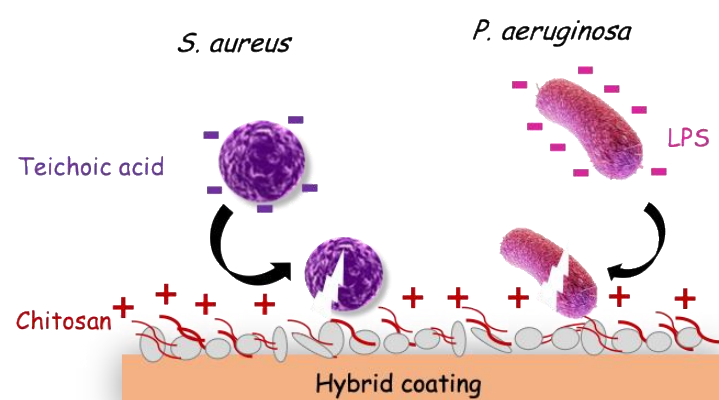

Hybrid coating
B

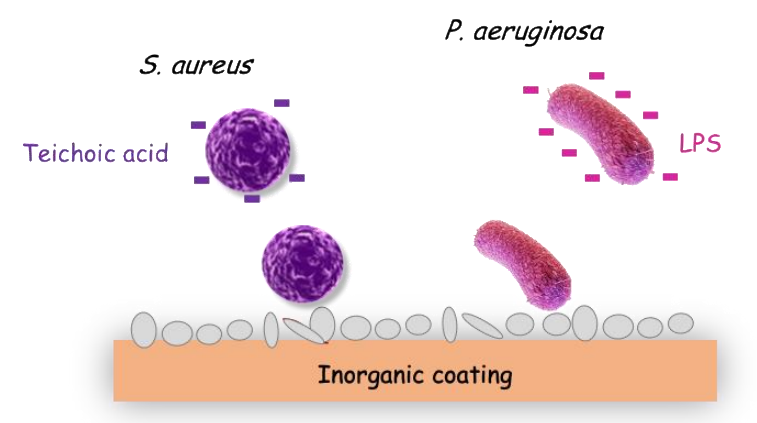

Scheme 1: Schematic representation of (A) the contact-killing effect of the Hybrid coating due to electrostatic interactions between negatively charged bacteria cell membrane and chitosan and (B) the no contact-killing effect of the Inorganic coating. 
P. aeruginosa membrane stability, ensured by interactions between lipopolysaccharide anionic groups (phosphate, carboxyl) and $\mathrm{Mg}^{2+}$ and $\mathrm{Ca}^{2+}$ divalent cations, could be compromised by chitosan, disturbing the bacterial wall or influencing the activity of degradative enzymes. The sensitivity of $P$. aeruginosa compared to $S$. aureus to the Hybrid coating could be explained by the wall architecture, as the lipopolysaccharides density is more important in $P$. aeruginosa wall than teichoic acid density in S. aureus one.

Antibacterial properties of stromal cells. Several reports showed that BM-MSCs conditioned media (CM) have an antibacterial effect on Gram-positive and Gram-negative strains. ${ }^{16,20,21,49}$ WJ-SCs and DPSCs are proposed as an alternative to BM-MSCs in bone reconstructive and regenerative medicine, but no study has been reported so far on the antibacterial effect of either WJ-SCs-CM and DPSCs-CM. Herein, the antibacterial properties of WJ-SCs-CM and DPSCs$\mathrm{CM}$, harvested after $72 \mathrm{~h}$ of culture on uncoated substrate, were investigated against S. aureus and $P$. aeruginosa strains. BM-MSCs-CM and cell free medium were used as positive and negative controls, respectively. After $24 \mathrm{~h}$ of incubation, $S$. aureus planktonic growth was significantly slowed down in the presence of the three stromal cell-CM versus the negative control. P. aeruginosa showed a higher susceptibility regarding DPSCs-CM, with about $20 \%$ of reduction in its planktonic growth versus the negative control while WJ-SCs-CM and BMMSCs-CM showed an insignificant decrease ( $<10 \%$ of reduction versus negative control) (Fig. 3A). Previous report demonstrated a modest antibacterial activity of BM-MSCs-CM against Gram-negative bacteria, which could be, however, enhanced with bacterial challenging. ${ }^{20}$ Efficacy of $\mathrm{CM}$ in reducing the biofilm formation by $S$. aureus and $P$. aeruginosa strains, on tissue plastic culture substrate (TCPS), was also investigated. After $24 \mathrm{~h}$ of incubation, the biofilm formation by $P$. aeruginosa was drastically hindered by the three stromal cell-CM. The biofilm formation by S. aureus was increased in the presence of WJ-SCs- 
CM and BM-MSCs-CM, while no effect in the case of DPSCs-CM was noticed (Fig. 3B). WJSCs and BM-MSCs released factors are thought to provide a source of stress that could reinforce $S$. aureus biofilm formation. Similar antibacterial and antibiofilm activities of the three stromal cell-CM were obtained when cultured on the Hybrid and Inorganic coatings versus uncoated substrate (Fig. SI-1). To sum up, whatever the substrate of culture, WJ-SCs and DPSCs have similar release-killing properties as BM-MSCs by secreting soluble factors exhibiting antibacterial and/or anti-biofilm effects. DPSCs seem to be more advantageous as the resulting released factors reduced both $S$. aureus and $P$. aeruginosa planktonic growth and biofilm formation. These results need to be comforted by further investigations through a deep analysis of CM components by peptidomic analysis but this is out of scope of the present study.

A

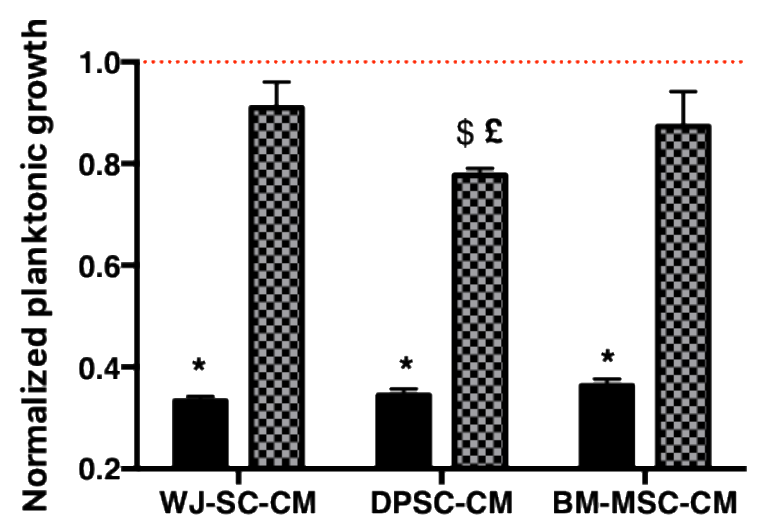

S. aureus
B

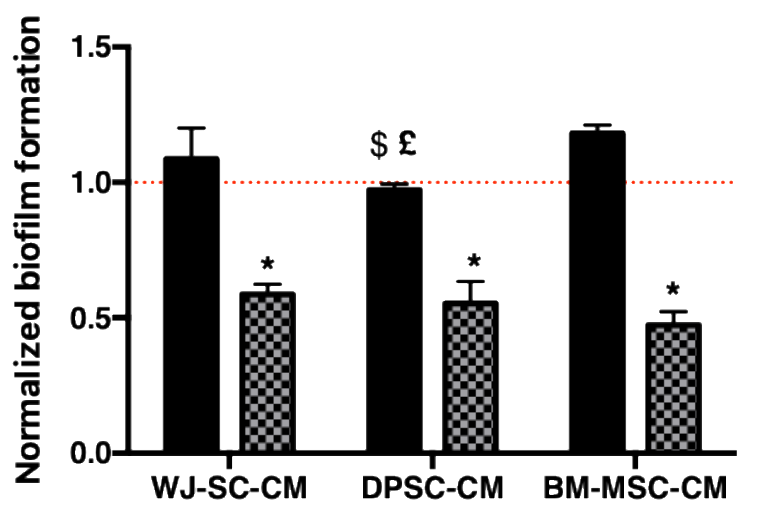

Be P. aeruginosa

Figure 3: Antibacterial and antibiofilm effects of conditioned media (CM) from stromal cells culture on uncoated substrate. (A) Planktonic growth of S. aureus and P. aeruginosa strains in the presence of CM. (B) Biofilm formation of $S$. aureus and $P$. aeruginosa strains in the presence of CM. The results, normalized to cell free culture medium (negative control), indicated by red dashed lines ( $\mathrm{n}=4$, * versus negative control, \$ versus WJ-SCs-CM, $£$ versus $\mathrm{BM}-\mathrm{MSCs}-\mathrm{CM}, p<0.05$; Mann \& Whitney test). 
Immunomodulatory properties of stromal cells. In the classic acute inflammatory episode, neutrophils are first recruited to the inflammatory site, followed by the infiltration of monocytes and lymphocytes, which replace neutrophils and orchestrate tissue repair. IL-6 and IL-8 are required for a normal neutrophil generation and function. ${ }^{50}$ In regard to monocytes, IL- 6 and MCP-1 play key roles in regulating monocyte/macrophage phenotypes and activities, favouring anti-inflammatory phenotypes associated with tissue healing. MSCs oppose bacterial infection through the secretion of specific cytokines with improved qualities. ${ }^{19} \mathrm{We}$ investigated the paracrine activities of WJ-SCs, DPSCs and BM-MSCs cultured on the Hybrid coating. Cells cultured on Inorganic coating and uncoated substrate were used as control. After one week of culture, stromal cell-CM were analysed by CBA. As WJ-SCs showed a higher basal secretion of IL-6, IL-8 and MCP-1 ( $50 \mathrm{ng} / \mathrm{mL})$ in comparison with DPSCs $(\sim 0.1 \mathrm{ng} / \mathrm{mL})$ and BMMSCs ( $5 \mathrm{ng} / \mathrm{mL})$ (Table 1), results presented in the Fig. 4 were normalized to stromal cellCM cultured on uncoated substrate.

Table 1: Paracrine activities of stromal cells. Released IL-8 (A), IL-6 (B) and MCP-1 (C) measured by CBA.

\begin{tabular}{|l|c|c|c|c|c|c|}
\hline & \multicolumn{2}{|c|}{ IL-8 (ng/mL) } & \multicolumn{2}{c|}{ IL-6 (ng/mL) } & \multicolumn{2}{c|}{ MCP-1 (ng/mL) } \\
\hline & Hybrid & Inorganic & Hybrid & Inorganic & Hybrid & Inorganic \\
\hline WJ-SCs & $29.14 \pm 2.2$ & $37.16 \pm 12.8$ & $14.53 \pm 3.1$ & $18.36 \pm 3.3$ & $80.67 \pm 2.9$ & $115.91 \pm 66.2$ \\
\hline DPSCs & $1.21 \pm 0.3$ & $1.96 \pm 0.4$ & $0.16 \pm 0.07$ & $0.19 \pm 0.08$ & $2.34 \pm 0.6$ & $2.17 \pm 0.4$ \\
\hline BM-MSCs & $4 \pm 1.7$ & $6.09 \pm 2.0$ & $8.86 \pm 2.9$ & $20.03 \pm 2.5$ & $4.23 \pm 1.5$ & $5.53 \pm 2.1$ \\
\hline
\end{tabular}

Interestingly, stromal cells behaved differently in contact with the two tested coatings (Fig. 4). The Hybrid coating reduced drastically the production of IL-8, IL-6 and MCP-1 $(<0.5$-fold versus uncoated substrate, $p<0.0001)$, while the Inorganic coating did not show any effect. DPSCs cultured on the Hybrid coating increased the IL-8 production (> 2.5-fold versus uncoated substrate, $p<0.05)$ with no effect on the two other cytokines. In contrast, DPSCs cultured on the Inorganic coating, exhibited an increase in IL-6, IL-8 and MCP-1 production (> 5-, 2- and 1.2-fold versus uncoated substrate, respectively, $p<0.03)$. Finally, BM-MSCs cultured on the Hybrid coating increased the IL-8 production (> 10-fold versus uncoated 
substrate, $p<0.01$ ), with an insignificant increase in IL-6 and MCP-1 ones (> 4- and 2-fold, versus uncoated substrate respectively, $p=0.09$ ). As DPSCs, BM-MSCs seemed more sensitive to the Inorganic coating as an increase in IL-8, IL-6 and MCP-1 production was noticed (> 17, 5- and 4-fold versus uncoated substrate, $p<0.01)$. The studied mediators have an important role in controlling the inflammatory response and tissue repair, but at high level, IL-6, IL-8 and MCP-1 could be involved in osteoclast activation, bone destruction and ineffective regeneration. ${ }^{51}$

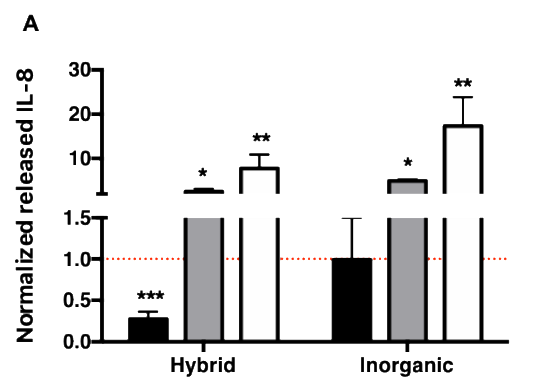

B

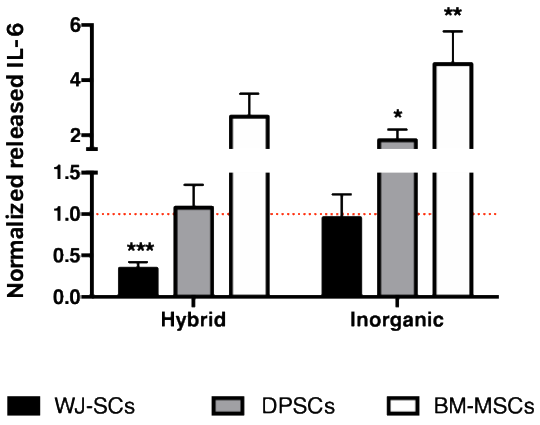

WJ-SCs $\square$ DPSCs $\square$ BM-MSCs

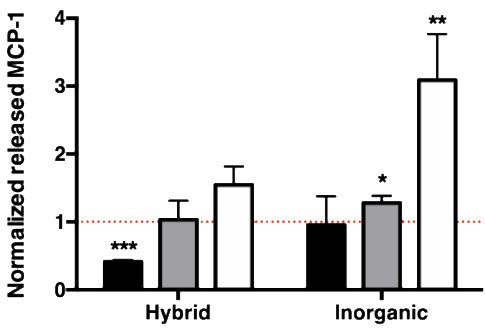

Hybrid

Figure 4: Paracrine activities of stromal cells cultured on the Hybrid and Inorganic coatings. CBA analysis of the released (A) IL-8, (B) IL-6 and (C) MCP-1 in stromal cell-CM. Results were normalized to cytokine level of stromal cells-CM cultured on uncoated substrate, indicated by red dashed lines $(\mathrm{n}=4$, * versus uncoated substrate $* p<0.05, * * p<0.01, * * * p<0.001 ;$ Mann \& Whitney test).

Considering the high level of secreted mediators by WJ-SCs (Table 1), our results suggested that DPSCs, close to BM-MSCs, could be beneficial to harness the acute inflammation. However, the Hybrid coating seems to be beneficial for WJ-SCs as a carrier to regulate the inflammatory process. 
S. aureus internalization by the stromal cells. Although the application of bone biomaterials is becoming common, their long-term durability is not guaranteed, and infection remains one of the main reasons for early failure in orthopaedics and trauma. ${ }^{4}$ S. aureus possesses numerous virulence factors, which play a role in the development and progression of osteomyelitis, through promoting invasion of bacteria, protection of bacteria from host defense mechanisms, and biofilm formation. Herein, we sought to investigate if the antibacterial features of the osteoinductive Hybrid coating provide a protective support for stromal cells, preventing $S$. aureus internalization. WJ-SCs, DPSCs and BM-MSCs cultured on the Hybrid coating were challenged for $3 \mathrm{~h}$ with $S$. aureus (acute infective model ${ }^{33}$ ). Inorganic coating was used as control. The rate of viable $S$. aureus was determined by colony forming unit (CFU) count following gentamicin-protective assay. ${ }^{33}$ The bacteria were able to invade the studied stromal cells cultured on uncoated substrate, with a rate of intracellular S. aureus of about $1.2 \%, 1 \%$ and $0.6 \%$ for WJ-SCs, DPSCs and BM-MSCs, respectively, without any statistical difference between cells (Fig. SI-2A). When cultured on the Hybrid coating (versus uncoated substrate), DPSCs and BM-MSCs presented a higher uptake of bacteria, while no effect was observed for WJ-SCs. In comparison to the Hybrid coating, the intracellular rate of S. aureus was increased for DPSCs cultured on the Inorganic coating and decreased for WJ-SCs and BM-MSCs $(<1.22$ and 1.68-fold versus the Hybrid coating, $p=0.4$ and $p=0.01$ respectively) (Fig. 5A). To sum up, the osteoinductive and antibacterial Hybrid coating might encourage the S. aureus entrance in DPSCs and BM-MSCs but not in WJ-SCs. 
A



B

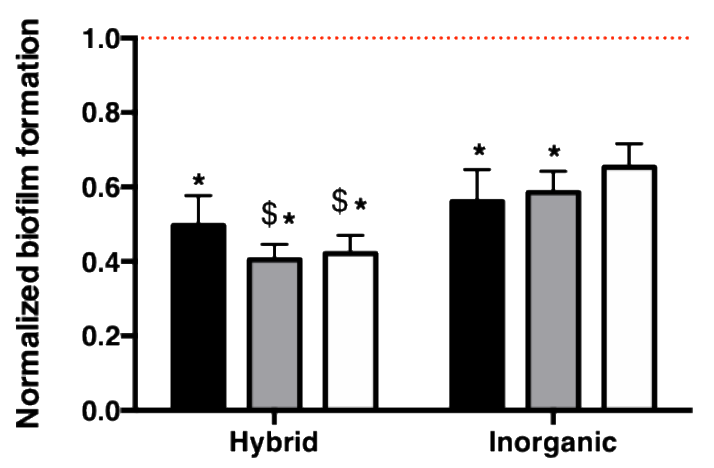

$\square$ WJ-SCs $\square$ DPSCs $\square$ BM-MSCs

Figure 5: Intracellular rate and biofilm formation of S. aureus. (A) Intracellular rate of S. aureus into stromal cells cultured on the Hybrid and Inorganic coatings. Results were normalized to the intracellular rate of bacteria into stromal cells cultured on uncoated substrate, indicated by the red dashed line. (B) Biofilm formation on TCPS by internalized bacteria. Results were normalized to the biofilm formation by internalized bacteria by stromal cells cultured on uncoated substrate, indicated by the red dashed line $(\mathrm{n}=4$, * versus uncoated substrate, $\$$ versus Inorganic; $p<0.01 ;$ Mann \& Whitney test).

Biofilm formation by internalized $S$. aureus. Biofilm formation is a critical virulence factor responsible for treatment failure and chronicity in orthopaedic device-related infections caused by $S$. aureus. ${ }^{31}$ In our laboratory, we observed the occurrence of cell lysis after infection, causing a release of internalized bacteria. ${ }^{33}$ Therefore, we evaluated the capabilities of internalized $S$. aureus to form biofilm on TCPS. First, no difference in biofilm formation capability was noticed between non-internalized bacteria and internalized bacteria by stromal cells cultured on uncoated substrate (Fig. SI-2B). In comparison to internalized bacteria by stromal cells cultured on uncoated substrate, a significant decrease in the biofilm formation of internalized bacteria was observed reaching at least 2-fold in reduction for the three stromal cells cultured on both coatings (Fig. 5B). There is an effect of the coating on the pathogenicity of internalized bacteria. Cultured on the antibacterial Hybrid coating, DPSCs and BM-MSCs internalized bacteria had significantly reduced pathogenicity in comparison to the Inorganic 
coating. Although the antibacterial Hybrid coating do not prevent S. aureus entrance and even favour it in certain cases, the internalized $S$. aureus had weaker capabilities to form biofilm in comparison to those internalized by stromal cells on uncoated substrate.

\section{Conclusion}

The antibacterial Hybrid coating, based on calcium phosphate and polysaccharides, provides contact-killing properties by disturbing the cell wall integrity of Gram-positive and Gramnegative bacteria. Its combination with stromal cells, able to release antibacterial agents and mediators of the innate immune response, constitutes an excellent strategy for fighting bacteria. Although the antibacterial Hybrid coating does not prevent S. aureus invasion into stromal cells and even favours it in certain cases, the internalized $S$. aureus have weaker capabilities to form biofilm in comparison to internalized bacteria by cells on uncoated substrate. Developing antibacterial strategies for bone tissue regenerative medicine by using stromal cells and/or versatile biomaterials should take into account the cell/bacteria interaction and their internalization.

\section{Supporting Information Available:}

The following file is available free of charge and provides a complementary Table related to the characterization of the Hybrid and Inorganic coatings and two Figures related to the antibacterial and antibiofilm effects of conditioned media from stromal cells cultured on the Hybrid and Inorganic coatings, and the biofilm formation by internalized bacteria by stromal cells cultured on uncoated substrate versus non-internalized ones. 


\section{Author Contributions:}

M. Dubus, J. Varin, P. Prada, L. Scomazzon and H. Rammal participated in experiments designing and performance. M. Dubus and H. Rammal in substrate coatings and stromal cell culture, J. Varin (cell infection and scanning electron microscopy), P. Prada and L. Scomazzon (CBA experiments and biofilm). H. Alem (Transmission electron microscopy). F. Reffuveille, F. Boulmedais, C. Mauprivez and H. Kerdjoudj participated in study design and manuscript writing. All authors reviewed the results and approved the final version of the manuscript.

Conflicts of Interest: The authors declare that the research was conducted in the absence of any commercial or financial relationships that could be construed as a potential conflict of interest.

Acknowledgments: This work was partially supported by « Interreg V France-WallonieVlaanderen program- TEXTOS » and «Fondation des Gueules Cassées, BioReg project». The authors are very grateful to the staff of Maternity (Pr. O. Graesslin) and Pôle Locomoteur (Dr. S. Diallo), Reims Hospital for providing umbilical cords and human bone marrow, respectively and the staff of the Core NanoMat, URCA (Dr. N. Bercu) and URCACyt (Dr. S. Audonnet).

\section{References}

(1) Li, H. K.; Rombach, I.; Zambellas, R.; Walker, A. S.; McNally, M. A.; Atkins, B. L.; Lipsky, B. A.; Hughes, H. C.; Bose, D.; Kümin, M.; et al., Oral versus Intravenous Antibiotics for Bone and Joint Infection. N. Engl. J. Med. 2019, 380, 425-436.

(2) Kavanagh, N.; Ryan, E. J.; Widaa, A.; Sexton, G.; Fennell, J.; O’Rourke, S.; Cahill, K. C.; Kearney, C. J.; O’Brien, F. J.; Kerrigan, S. W. Staphylococcal Osteomyelitis: Disease Progression, Treatment Challenges, and Future Directions. Clin. Microbiol. Rev. 2018, 31, e00084-17.

(3) Ahmadabadi, H. Y.; Yu, K.; Kizhakkedathu, J. N. Surface modification approaches for prevention of implant associated infections. Colloids Surf. B Biointerfaces. 2020, 193, 11111.

(4) Romanò, C. L.; Tsuchiya, H.; Morelli, I.; Battaglia, A. G.; Drago, L. Antibacterial Coating of Implants: Are We Missing Something? Bone Joint. Res. 2019, 8, 199-206. 
(5) Raphel, J.; Holodniy, M.; Goodman, S. B.; Heilshorn S. C. Multifunctional Coatings to Simultaneously Promote Osseointegration and Prevent Infection of Orthopaedic Implants. Biomaterials 2016, 84, 301-314.

(6) Afewerki, S.; Bassous, N.; Harb, S.; Palo-Nieto, C.; Ruiz-Esparza, G. U.; Marciano, F. R.; Webster, T. J.; Furtado, A. S. A.; Lobo, A. O. Advances in Dual Functional Antimicrobial and Osteoinductive Biomaterials for Orthopaedic Applications. Nanomedicine. 2020, 24, 102143.

(7) Ahmed, W.; Zhai, Z.; Gao, C. Adaptive Antibacterial Biomaterial Surfaces and Their Applications. Mater. Today Bio 2019, 2, 100017.

(8) Zhu, X.; Loh, X. J. Layer-by-Layer Assemblies for Antibacterial Applications. Biomater. Sci. 2015, 3, 1505-1518.

(9) Rammal, H.; Harmouch, C.; Lataillade, J. J.; Laurent Maquin, D.; Labrude, P.; Menu, P.; Kerdjoudj, H. Stem Cells: A Promising Source for Vascular Regenerative Medicine. Stem Cells Dev. 2014, 23, 2931-2949.

(10) Galipeau, J.; Sensébé, L. Mesenchymal Stromal Cells: Clinical Challenges and Therapeutic Opportunities. Cell Stem Cell 2018, 22, 824-833.

(11) Stefańska, K.; Ożegowska, K.; Hutchings, G.; Popis, M.; Moncrieff, L.; Dompe, C.; Janowicz, K.; Pieńkowski, W.; Gutaj, P.; Shibli, J. A. et al. Human Wharton's Jelly-Cellular Specificity, Stemness Potency, Animal Models, and Current Application in Human Clinical Trials. J. Clin. Med. 2020, 9, 1102.

(12) Leyendecker Junior, A.; , Gomes Pinheiro, C. C.; Fernandes T. L.; Bueno D. F. The Use of Human Dental Pulp Stem Cells for in Vivo Bone Tissue Engineering: A Systematic Review. J. Tissue Eng. 2018, 9, 2041731417752766.

(13) Ercal, P.; Pekozer, G. G.; Kose, G. T. Dental Stem Cells in Bone Tissue Engineering: Current Overview and Challenges. Cell Biology Transl. Med. 2018, 1107, 113-127.

(14) Horak, J.; Nalos, L.; Martinkova V.; Tegl, V.; Vistejnova, L.; Kuncova, J.; Kohoutova, M.; Jarkovska, D.; Dolejsova M.; Benes J., et al. Evaluation of Mesenchymal Stem Cell Therapy for Sepsis: A Randomized Controlled Porcine Study. Front. Immunol. 2020, 11, 126.

(15) Hayes, M.; Curley, G.; Ansari, B.; Laffey, J. G. Clinical Review: Stem Cell Therapies for Acute Lung Injury/Acute Respiratory Distress Syndrome - Hope or Hype? Critical Care 2012, 16, 205.

(16) Sutton, M. T.; Fletcher, D.; Ghosh, S. K.; Weinberg, A.; van Heeckeren, R.; Kaur, S.; Sadeghi, Z.; Hijaz, A.; Reese, J.; Lazarus, H. M.; et al. Antimicrobial Properties of Mesenchymal Stem Cells: Therapeutic Potential for Cystic Fibrosis Infection, and Treatment. Stem Cells Int. 2016, 2016, 12.

(17) Caretti, A.; Peli, V.; Colombo, M.; Zulueta, A. Lights and Shadows in the Use of Mesenchymal Stem Cells in Lung Inflammation, a Poorly Investigated Topic in Cystic Fibrosis. Cells 2020, 9, 20. 
(18) Golchin, A.; Seyedjafari, E.; Ardeshirylajimi, A. Mesenchymal Stem Cell Therapy for COVID-19: Present or Future. Stem Cell Rev. Rep. 2020, 16, 427-433.

(19) Mezey, É.; Nemeth, K. Mesenchymal Stem Cells and Infectious Diseases: Smarter than Drugs. Immunol. Lett. 2015, 168, 208-214.

(20) Krasnodembskaya, A.; Song, Y.; Fang, X.; Gupta, N.; Serikov, V.; Lee, J.-W.; Matthay, M. A. Antibacterial Effect of Human Mesenchymal Stem Cells Is Mediated in Part from Secretion of the Antimicrobial Peptide LL-37. Stem Cells 2010, 28, 2229-2238.

(21) Alcayaga-Miranda, F.; Cuenca, J.; Khoury, M. Antimicrobial Activity of Mesenchymal Stem Cells: Current Status and New Perspectives of Antimicrobial Peptide-Based Therapies. Front. Immunol. 2017, 8, 339.

(22) Xiao, D.; Zhang, J.; Zhang, C.; Barbieri, D.; Yuan, H.; Moroni, L.; Feng, G. The Role of Calcium Phosphate Surface Structure in Osteogenesis and the Mechanisms Involved. Acta Biomater. 2020, 106, 22-33.

(23) Kashirina, A.; Yao, Y.; Liu, Y.; Leng, J. Biopolymers as Bone Substitutes: A Review. Biomater. Sci. 2019, 7, 3961-3983.

(24) Ding, C.; Chen, Z.; Li, J. From Molecules to Macrostructures: Recent Development of Bioinspired Hard Tissue Repair. Biomater. Sci. 2017, 5, 1435-1449

(25) Jahan, K.; Tabrizian, M. Composite Biopolymers for Bone Regeneration Enhancement in Bony Defects. Biomater. Sci. 2015, 4, 25-39.

(26) Rammal, H.; Dubus, M.; Aubert, L.; Reffuveille, F.; Laurent-Maquin, D.; Terryn, C.; Schaaf, P.; Alem, H.; Francius, G.; Quilès, F.; et al. Bioinspired Nanofeatured Substrates: Suitable Environment for Bone Regeneration. ACS Appl. Mater. Interfaces 2017, 9, 1279112801.

(27) Rammal, H.; Entz, L.; Dubus, M.; Moniot, A.; Bercu, N. B.; Sergheraert, J.; Gangloff, S. C.; Mauprivez, C.; Kerdjoudj, H. Osteoinductive Material to Fine-Tune Paracrine Crosstalk of Mesenchymal Stem Cells With Endothelial Cells and Osteoblasts. Front. Bioeng. Biotechnol. 2019, 7, 256.

(28) Dubus, M.; Rammal, H.; Alem, H.; Bercu, N. B.; Royaud, I.; Quilès, F.; Boulmedais, F.; Gangloff, S. G.; Mauprivez, C.; Kerdjoudj, H. Boosting Mesenchymal Stem Cells Regenerative Activities on Biopolymers-Calcium Phosphate Functionalized Collagen Membrane. Colloids Surf. B Biointerfaces 2019, 181, 671-679.

(29) Tande, A. J.; Patel, R. Prosthetic Joint Infection. Clin. Microbiol. Rev. 2014, 27, 302345.

(30) Parvizi, J.; Shohat, N.; Gehrke, T. Prevention of Periprosthetic Joint Infection: New Guidelines. Bone Joint. J. 2017, 99-B, 3-10.

(31) Masters, E. A.; Trombetta, R. P.; de Mesy Bentley, K. L.; Boyce, B. F.; Gill, A. L.; Gill, 
S. R.; Nishitani, K.; Ishikawa, M.; Morita, Y.; Ito, H.; et al. Evolving Concepts in Bone Infection: Redefining "Biofilm", "Acute vs. Chronic Osteomyelitis", "the Immune Proteome" and "Local Antibiotic Therapy." Bone Res. 2019, 7, 1-18.

(32) Josse, J.; Velard, F.; Mechiche Alami, S.; Brun, V.; Guillaume, C.; Kerdjoudj, H.; Lamkhioued, B.; Gangloff, S. C. Increased Internalization of Staphylococcus Aureus and Cytokine Expression in Human Wharton's Jelly Mesenchymal Stem Cells. Biomed. Mater. Eng. 2014, 24, 27-35.

(33) Alva-Murillo, N.; López-Meza, J. E.; Ochoa-Zarzosa, A. Nonprofessional Phagocytic Cell Receptors Involved in Staphylococcus Aureus Internalization. Biomed. Res. Int. 2014, 2014, 9.

(34) Abdulrehman, T.; Qadri, S.; Skariah, S.; Sultan, A.; Mansour, S.; Azzi, J.; Haik, Y. Boron Doped Silver-Copper Alloy Nanoparticle Targeting Intracellular $\underline{S}$. Aureus in Bone Cells. PLOS ONE 2020, 15, e0231276.

(35) Wen, Q.; Gu, F.; Sui, Z.; Su, Z.; Yu, T. The Process of Osteoblastic Infection by Staphylococcus Aureus. Int. J. Med. Sci. 2020, 17, 1327-1332.

(36) Josse, J.; Laurent, F.; Diot, A. Staphylococcal Adhesion and Host Cell Invasion: Fibronectin-Binding and Other Mechanisms. Front. Microbiol. 2017, 8, 2433.

(37) Moursi, A. M.; Globus, R. K.; Damsky, C. H. Interactions between Integrin Receptors and Fibronectin Are Required for Calvarial Osteoblast Differentiation in Vitro. J. Cell. Sci. 1997, 110, 2187-2196.

(38) Mechiche Alami, S.; Gangloff, S. C.; Laurent-Maquin, D.; Wang, Y.; Kerdjoudj, H. Concise Review: In Vitro Formation of Bone-Like Nodules Sheds Light on the Application of Stem Cells for Bone Regeneration. Stem Cells Transl. Med. 2016, 5, 1587-1593.

(39) Gupta, P.; Sarkar, S.; Das, B.; Bhattacharjee, S.; Tribedi, P. Biofilm, Pathogenesis and Prevention-a Journey to Break the Wall: A Review. Arch. Microbiol. 2016, 198, 1-15.

(40) Cado, G.; Kerdjoudj, H.; Chassepot, A.; Lefort, M.; Benmlih, K.; Hemmerlé, J.; Voegel, J.-C.; Jierry, L.; Schaaf, P.; Frère, Y.; Boulmedais, F. Polysaccharide Films Built by Simultaneous or Alternate Spray: A Rapid Way to Engineer Biomaterial Surfaces. Langmuir 2012, 28, 8470-8478

(41) Rammal, H.; Bour, C.; Dubus, M.; Entz, L.; Aubert, L.; Gangloff, S. C.; Audonnet, S.; Bercu, N. B.; Boulmedais, F.; Mauprivez, C.; Kerdjoudj, H. Combining Calcium Phosphates with Polysaccharides: A Bone-Inspired Material Modulating Monocyte/Macrophage Early Inflammatory Response. Int. J. Mol. Sci. 2018, 19, 3458.

(42) Mechiche Alami, S.; Rammal, H.; Boulagnon-Rombi, C.; Velard, F.; Lazar, F.; Drevet, R.; Laurent Maquin, D.; Gangloff, S. C.; Hemmerlé, J.; Voegel, et al. Harnessing Wharton's Jelly Stem Cell Differentiation into Bone-like Nodule on Calcium Phosphate Substrate without Osteoinductive Factors. Acta Biomater. 2017, 49, 575-589.

(43) van de Lagemaat, M.; Grotenhuis, A.; van de Belt-Gritter, B.; Roest, S.; Loontjens, T. 
J. A.; Busscher, H. J.; van der Mei, H. C.; Ren, Y. Comparison of Methods to Evaluate Bacterial Contact-Killing Materials. Acta Biomater. 2017, 59, 139-147.

(44) Drago, L.; Cappelletti, L.; De Vecchi, E.; Pignataro, L.; Torretta, S.; Mattina, R. Antiadhesive and Antibiofilm Activity of Hyaluronic Acid against Bacteria Responsible for Respiratory Tract Infections. APMIS. 2014, 122, 1013-1019.

(45) Marcuzzo, A. V.; Tofanelli, M.; Boscolo Nata, F.; Gatto, A.; Tirelli, G. Hyaluronate Effect on Bacterial Biofilm in ENT District Infections: A Review. APMIS. 2017, 125, 763-772.

(46) Kong, M.; Chen, X. G.; Xing, K.; Park, H. J. Antimicrobial Properties of Chitosan and Mode of Action: A State of the Art Review. Int. J. Food Microbiol. 2010, 144, 51-63.

(47) Raafat, D.; Sahl, H. Chitosan and Its Antimicrobial Potential - a Critical Literature Survey. Microb. Biotechnol. 2009, 2, 186-201.

(48) Raafat, D.; von Bargen, K.; Haas, A.; Sahl, H.-G. Insights into the Mode of Action of Chitosan as an Antibacterial Compound. Appl. Environ. Microbiol. 2008, 74, 3764-3773.

(49) Dubus, M.; Varin. J.; Papa, S.; Rammal, H.; Chevrier, J.; Maisonneuve, E.; Mauprivez, C.; Mongaret, C.; Gangloff, S. C.; Reffuveille, F.; Kerdjoudj, H. Interaction of Cutibacterium Acnes With Human Bone Marrow Derived Mesenchymal Stem Cells: A Step Toward Understanding Bone Implant- Associated Infection. Acta Biomater. 2020, 104, 124-134.

(50) Buckley, C. D.; Gilroy, D. W.; Serhan, C. N. Pro-Resolving Lipid Mediators and Mechanisms in the Resolution of Acute Inflammation. Immunity 2014, 40, 315-327.

(51) Mountziaris, P. M.; Mikos, A. G. Modulation of the Inflammatory Response for Enhanced Bone Tissue Regeneration. Tissue Eng. Part B Rev. 2008, 14, 179-186. 